\title{
NON-DESTRUCTIVE TESTING OF DUPLEX WELDING JOINTS
}

\author{
Roxana-Alexandra GHEȚA, Maria-Cristina DIJMĂRESCU, \\ Laurenția BICHIR, Gabriel Marius DUMITRU
}

Politehnica University of Bucharest, No. 313, Splaiul Independenței, sector 6, Bucharest, Romania e-mail: roxana_gheta@yahoo.com,cristina_dijmarescu@yahoo.com, laura_bichir@yahoo.com, gmdumitru@yahoo.com

\begin{abstract}
This paper presents results of non-destructive examination of welding belt and the heat affected zone. The samples were made using sheets of duplex stainless steel, welded through the method of manual welding with coated electrode, by utilizing 4 types of electrodes. The specimens were subjected to different nondestructive examination methods in order to identify the defects, to establish new efficient procedures and to achieve high productivity in detection of defects appeared.
\end{abstract}

KEYWORDS: non-destructive testing, duplex stainless steel, welding joints

\section{Introduction}

Nowadays the non-destructive examination is used to verify the integrity of the products starting from the early stages of the manufacturing processes to the last stages of the product exploitation process. So, to know which method to use for each type of material it is essential to reduce the non-destructive testing related costs [1-3].

Developed over 70 years ago, duplex type stainless steels initially appeared to combat corrosion problems caused by aggressive chemical process fluids or seawater used for cooling. The name is due to the mixed microstructure formed of equal proportions of ferrite and austenite. Chemical composition based on high $\mathrm{Cr}, \mathrm{Ni}$ and $\mathrm{Mo}$ content, improves resistance to intergranular and pitting corrosion. As a result of the development of offshore oil and gas exploitations, the next generation of duplex steels was developed by the deliberate addition of nitrogen as an alloying element, which improves both the tenacity of the thermally influenced area of the joint and the corrosion resistance in ion-containing environments of chlorine $[1,4,5]$.

This paper presents the application of different non-destructive methods in order to identify the imperfections in duplex stainless-steel welded joints with four different types of electrodes. Obtaining different structures in the welded seams can be a problem for the non-destructive examination. So, the main focus of the paper is to establish which method provides more information about the welded seam.

\section{Experimental data}

\subsection{Samples description}

Steel sheet of duplex stainless steel $\mathrm{X} 2 \mathrm{CrNiMoN} 22-5-3$ of $15 \mathrm{~mm}$ thickness were used in the study presented in this paper. The chemical composition and the mechanical proprieties of the base material are presented in Table 1 and Table 2.

Table 1. Chemical composition of the base material X2CrNiMoN22-5-3

\begin{tabular}{cccccccccc}
\hline $\begin{array}{c}\text { Chemical } \\
\text { Composition }\end{array}$ & $\mathrm{C} \%$ & $\mathrm{Cr} \%$ & $\mathrm{Mn} \%$ & $\mathrm{Mo} \%$ & $\mathrm{~N} \%$ & $\mathrm{Ni} \%$ & $\mathrm{P} \%$ & $\mathrm{~S} \%$ & $\mathrm{Si} \%$ \\
\hline UNS & 0.30 & $22.0-23.0$ & $2.00 \max$ & $3.00-3.50$ & $0.14-0.20$ & $4.50-6.50$ & $\begin{array}{r}0.030 \\
\max \end{array}$ & $\begin{array}{c}0.020 \\
\max \end{array}$ & $\begin{array}{c}1.00 \\
\max \end{array}$ \\
\hline
\end{tabular}


THE ANNALS OF "DUNAREA DE JOS" UNIVERSITY OF GALATI

FASCICLE IX. METALLURGY AND MATERIALS SCIENCE

No. 4 - 2018, ISSN 2668-4748; e-ISSN 2668-4756

Article DOI: https://doi.org/10.35219/mms.2018.4.07

Table 2. Mechanical proprieties of the base material X2CrNiMoN22-5-3

\begin{tabular}{cc}
\hline Properties & Value \\
\hline Drip limit $\left(\mathrm{R}_{\mathrm{p} 02}\right)$ & $\min .480 \mathrm{~N} / \mathrm{mm}^{2}$ \\
Tensile strength $\left(\mathrm{R}_{\mathrm{m}}\right)$ & $\min .680 \mathrm{~N} / \mathrm{mm}^{2}$ \\
Elongation $\left(\mathrm{A}_{5}\right)$ & $\min .25 \%$ \\
Hardness $(\mathrm{HB})$ & $\max .290$ \\
Resilience $(\mathrm{KCV})$ & $\min .100 \mathrm{~J} / \mathrm{cm}^{2}$ \\
\hline
\end{tabular}

\subsection{Welding process}

Samples of $200 \mathrm{~mm} \times 50 \mathrm{~mm}$ x $15 \mathrm{~mm}$ were welded using the SMAW process. For the experiment were used four types of electrodes as following ASP308MN, OK68.81, Duplex 25/16/3 and E309Mo17. The chemical composition of the filling materials is presented in Table 3 and the mechanical properties in Table 4. The welding parameters used are presented in Table 5.

The configuration of the chosen groove and the number of layers deposited are presented in Figure 1.

The samples were welded in horizontal position on each sample were used 2 types of electrodes as it can be seen in Figure 2.

The resulted welded samples are presented in Figure 3.

Table 3. Chemical composition of the filling materials

\begin{tabular}{|c|c|c|c|c|c|c|c|c|c|c|c|c|c|c|}
\hline Filler material & $\begin{array}{c}\mathrm{C} \\
{[\%]}\end{array}$ & $\begin{array}{c}\mathrm{Si} \\
{[\%]}\end{array}$ & $\begin{array}{l}\mathrm{M} \\
{[\%}\end{array}$ & & $\begin{array}{c}\mathrm{P} \\
{[\%]}\end{array}$ & $\begin{array}{c}\mathrm{S} \\
{[\%]}\end{array}$ & \multicolumn{2}{|c|}{$\begin{array}{c}\mathrm{Cr} \\
{[\%]} \\
\end{array}$} & \multicolumn{2}{|c|}{$\begin{array}{c}\mathrm{Ni} \\
{[\%]}\end{array}$} & $\begin{array}{l}\mathrm{Mc} \\
{[\%}\end{array}$ & & $\begin{array}{c}\mathrm{Cu} \\
{[\%]}\end{array}$ & $\begin{array}{c}\mathrm{N} \\
{[\%]}\end{array}$ \\
\hline ASP308Mn & $\stackrel{\circ}{\circ}$ & ?ִ & 8 & & ' & ' & & : & \multicolumn{2}{|c|}{$\stackrel{8}{\circ}$} & ' & & ' & ' \\
\hline OK68.81 & 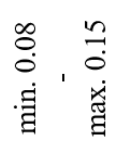 & 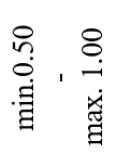 & 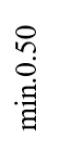 & $\begin{array}{l}\stackrel{8}{-} \\
\dot{x} \\
\stackrel{\sharp}{\sharp}\end{array}$ & $\begin{array}{l}\stackrel{0}{0} \\
\stackrel{0}{0} \\
\dot{x} \\
\stackrel{\Xi}{\sharp}\end{array}$ & $\begin{array}{l}\stackrel{\leftrightarrow}{0} \\
\stackrel{0}{0} \\
\dot{x} \\
\stackrel{\Xi}{\Xi}\end{array}$ & 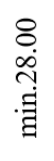 & $\begin{array}{l}8 \\
\dot{0} \\
\dot{m} \\
\dot{x} \\
\ddot{g}\end{array}$ & $\begin{array}{l}8 \\
\text { ஷे } \\
. \dot{\Xi}\end{array}$ & $\begin{array}{l}\stackrel{0}{0} \\
\stackrel{+}{\not} \\
\dot{x} \\
\stackrel{g}{g}\end{array}$ & 5 & & 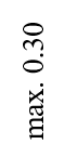 & \begin{tabular}{l}
$n$ \\
\hdashline \\
$\dot{d}$ \\
$\stackrel{\leftrightarrow}{a}$
\end{tabular} \\
\hline INOX $25 / 16 / 3$ & $\begin{array}{l}\text { ¿े } \\
\dot{\vec{v}}\end{array}$ & $\begin{array}{l}\infty \\
\stackrel{0}{0}\end{array}$ & 5 & & ' & ' & & th & & & \& & & 1 & ' \\
\hline E309Mo17 & 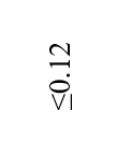 & 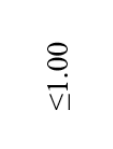 & $\begin{array}{l}0 \\
n \\
0 \\
\dot{1}\end{array}$ & 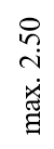 & $\begin{array}{l}\text { ¿े } \\
\dot{\vec{V}}\end{array}$ & $\begin{array}{l}\text { ôे } \\
\dot{\vec{v}}\end{array}$ & $\begin{array}{l}8 \\
\text { त } \\
. \dot{\Xi}\end{array}$ & $\begin{array}{l}8 \\
\ddot{n} \\
\dot{x} \\
\text { ฮี }\end{array}$ & $\begin{array}{l}8 \\
\text { ¿ } \\
. \dot{\Xi}\end{array}$ & $\begin{array}{l}8 \\
\dot{+} \\
\dot{x} \\
\stackrel{\not}{\Xi}\end{array}$ & 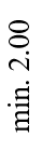 & $\begin{array}{l}8 \\
\dot{r} \\
\dot{x} \\
\ddot{\exists}\end{array}$ & 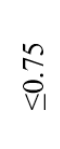 & ' \\
\hline
\end{tabular}

Table 4. The mechanical properties of the filler materials

\begin{tabular}{ccccc}
\hline Properties & ASP308Mn & OK68.81 & INOX 25/16/3 & E309Mo17 \\
\hline Yield Strength [N/mm ${ }^{2}$ ] & 420 & 610 & $\geq 490$ & - \\
Tensile Strength [N/mm $\left.{ }^{2}\right]$ & 640 & 790 & $\geq 670$ to 810 & 550 \\
Elongation [\%] & 35 & 25 & $\geq 25$ & 30 \\
Impact Strength [J] at $20^{\circ} \mathrm{C}$ & 100 & 30 & 47 & - \\
\hline
\end{tabular}



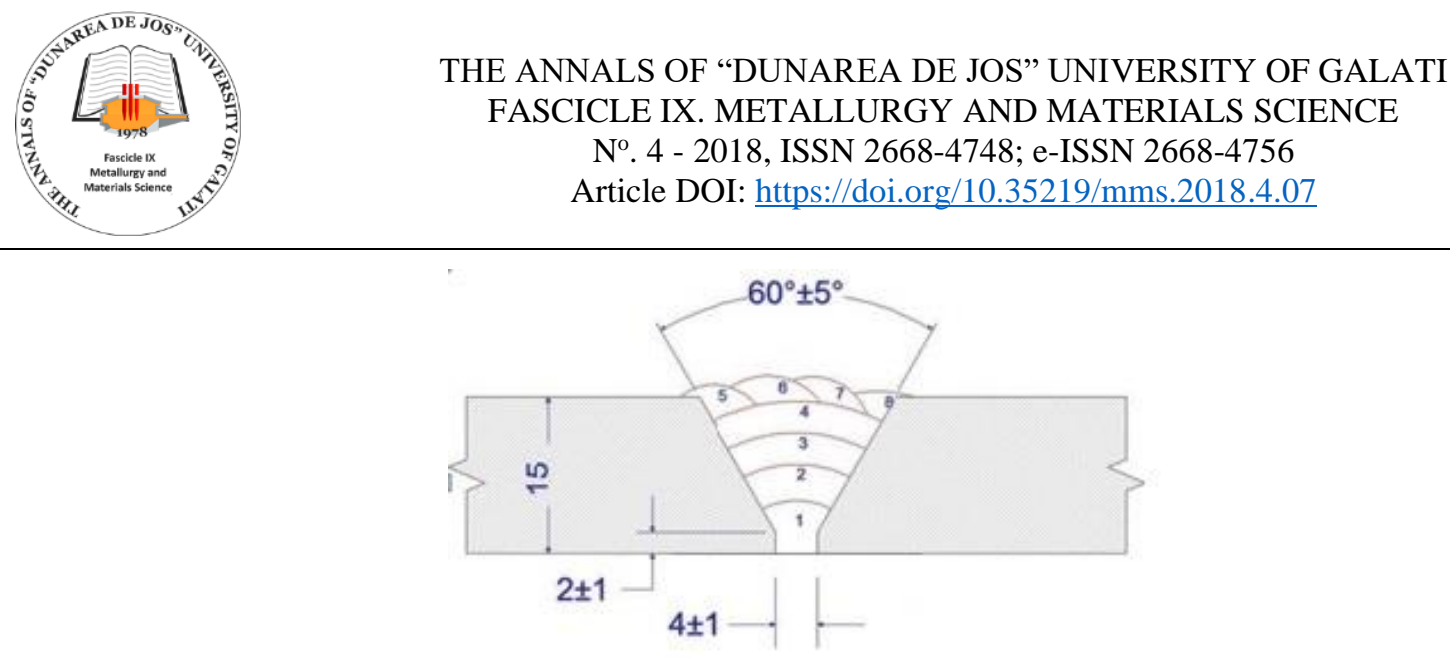

Fig. 1. The groove configuration and the layer layout $1 \div 8$ - number of layers
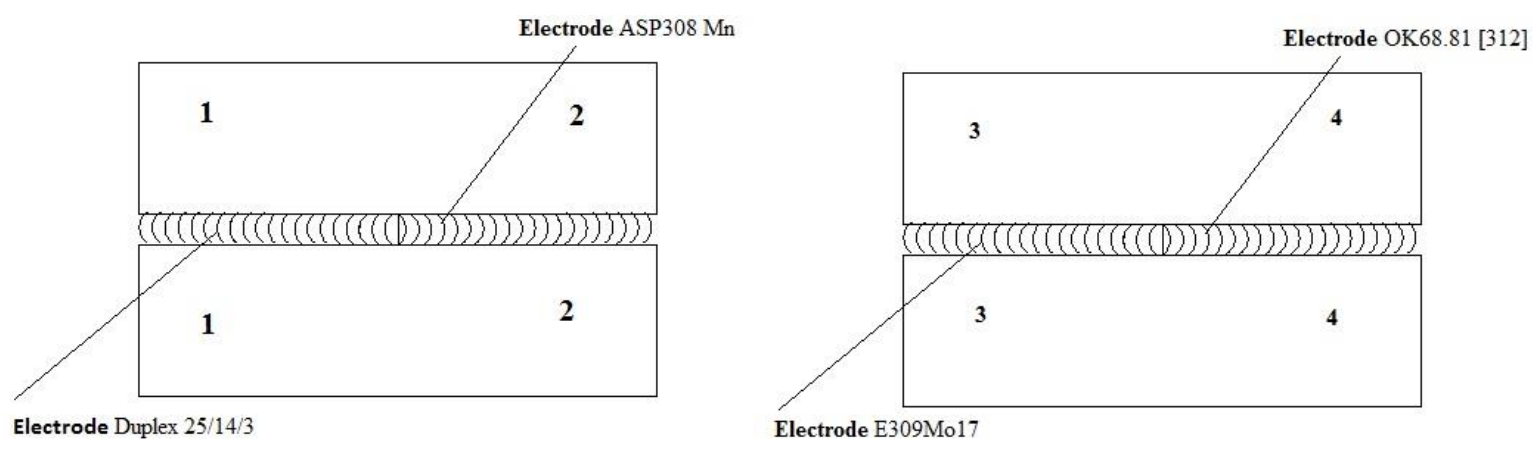

Fig. 2. Position of the electrodes used 1 - Duplex 25/14/3 electrode, 2 - ASP308 Mn electrode, 3 E309Mo17electrode, 4 - OK68.81 electrode

Table 5. Welding parameters

\begin{tabular}{cccc}
\hline Type of electrode & $\begin{array}{c}\text { Number of } \\
\text { layers }\end{array}$ & $\begin{array}{c}\text { Welding } \\
\text { current } \\
{[\mathrm{A}]}\end{array}$ & $\begin{array}{c}\text { Voltage, } \mathrm{U}_{\mathrm{a}} \\
{[\mathrm{V}]}\end{array}$ \\
\hline Duplex 25/14/3 & 8 & $120 \pm 10$ & $20 \pm 5$ \\
ASP308 Mn & 8 & $115 \pm 10$ & $20 \pm 5$ \\
E309Mo17 & 8 & $110 \pm 10$ & $20 \pm 5$ \\
OK68.81 & 8 & $110 \pm 10$ & $20 \pm 5$ \\
\hline
\end{tabular}

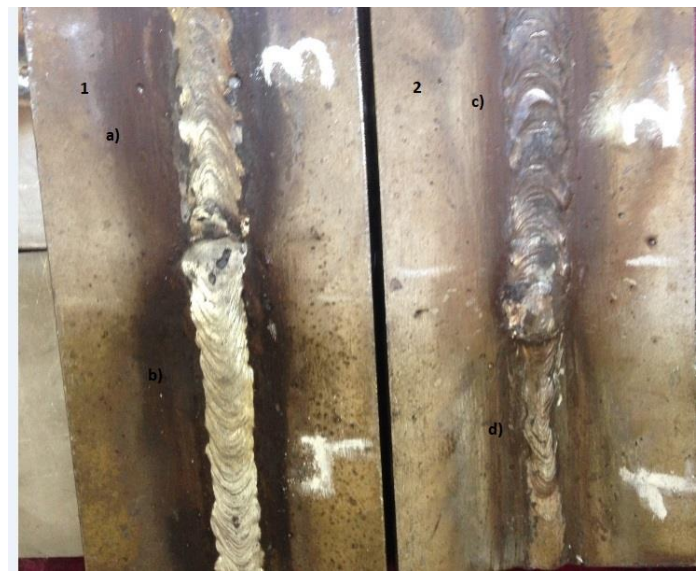

Fig. 3. Welded sample 1 - sample 1, a) - E309Mo17 electrode, b) - OK68.81electrode 2 - sample 2, c) - ASP308 Mn electrode, d) - Duplex 25/14/3 electrode 


\subsection{Non-destructive examination of the samples}

To analyse the integrity the welding joints and to see which method shows a better result, the samples were subjected to non-destructive examinations. The samples were pre-cleaned before starting the non-destructive examination. For the examination, 4 methods were used: Visual Testing, Penetrant Testing and Ultrasonic Testing. The nondestructive examination was applied to see if there are any macroscopic flows in the welded seam and in the basic materials.

\section{Visual Testing}

The examination was made using the direct visual testing. On the samples there could be identified slag inclusions, spatter and scratches made by the tools used.

\section{Dry Penetrant Testing}

The examination with dry penetrant testing was conducted at the ambient temperature of $20^{\circ} \mathrm{C}$.

For the examination with penetrant testing, the following steps were undertaken:

- Preparation and pre-cleaning of the surface the samples were chemically cleaned by degreasing using the METAFLUX 70-9801 cleaner;

- Surface drying - it was forced by a hot air jet; Figure 4.

- Penetrant application and dwell time - see

- penetrant - METAFLUX 70-9802;

- the penetrant was applied on the surface by spraying:

- Dwell time - 10 min.

- Excess penetrant removal - it was made by washing;

- Surface drying - it was forced by a hot air jet;

- Developer application - see Figure 5:

- developer - METAFLUX 70-9803;

- the developer was applied in a uniform and thin layer, on the entire surface to be examined, only after having been well shaken beforehand;

- after application of the developer, the examined surface was left to dry at room temperature;

- the development time starts immediately after the surface has dried, the development time being $30 \mathrm{~min}$;

- Inspection - interpretation of the results was made at the end of the development time;

- Cleaning the surface.

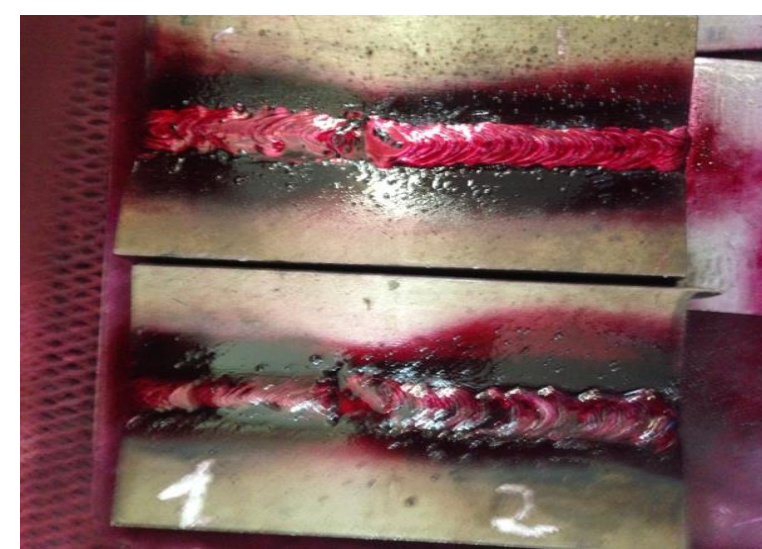

Fig. 4. Penetrant Application

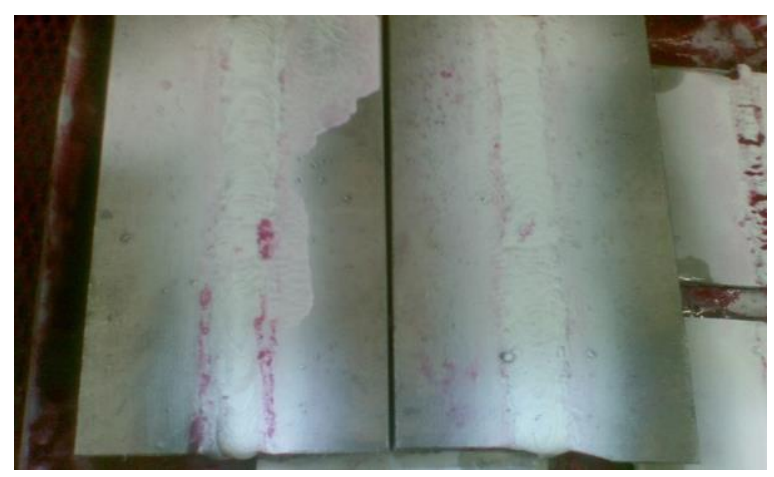

Fig. 5. Developer Application

The imperfections identified with the dry penetrant testing were:

- Surface imperfections (cavities, spatter, surface pore),

- Slag inclusions.

\section{Magnetic Testing}

In order to conduct the magnetic testing, the following steps were undertaken:

- Preparation of the test specimen - the samples were chemically cleaned by degreasing;

- Magnetization of the test specimen - it was conducted using electromagnets, as it can be seen in Figure 6. In the samples was created a longitudinal magnetic field composed by magnetic lines of force that run parallel to the long axis of the welded seam;

- Application of the magnetic powder - it was conducted using a suspension of fluorescent magnetic particles in low-viscos carrier oil with special additives PFINDER 150. With PFINDER 150 surface defects of materials can be indicated under UV-light. The suspension was applied on the surface by spraying;

- Viewing and recording of indications - The magnetic field was oriented so that its line of force was perpendicular to the maximum size of the imperfection, see Figure 7; 
- Demagnetization - to demagnetize the samples, AC current was used gradually to reduce the applied current to zero;

- Cleaning the surface - after the examination the samples was chemically cleaned by degreasing.

After examining the samples with this method no imperfections were identified on the welded seam and the adjacent areas.

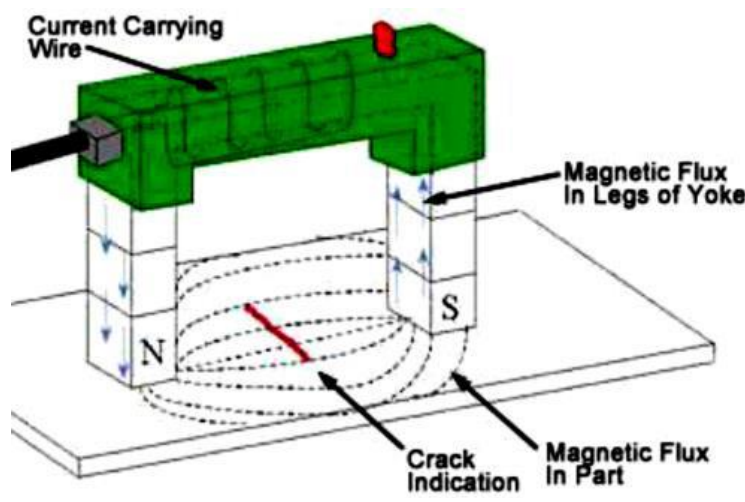

Fig. 6. The electromagnets - method principle

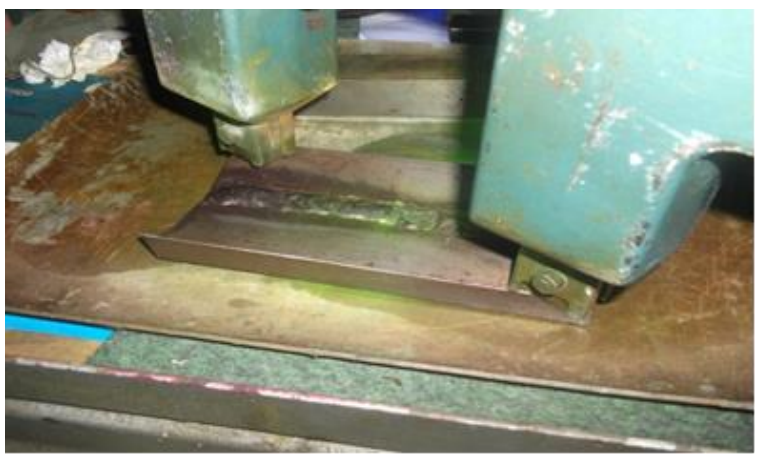

Fig. 7. Magnetization of the samples

\section{Ultrasound Testing}

To conduct the examination, a Krautkramer USM-35 device was used, along with an angle beam transducer.

The following equipment was used:

- Krautkramer USM-35 - see Figure 8;

- Angle beam transducer: 70 - AM4R-8x970

- Calibration block used - A1;

- Couplant medium - grease;

- Frequency - $4 \mathrm{MHz}$.

The ultrasound testing conducted on the samples is presented in Figure 9.

Using the ultrasound testing in sample 2, it was identified a lack of fusion between the root layer and second layer.

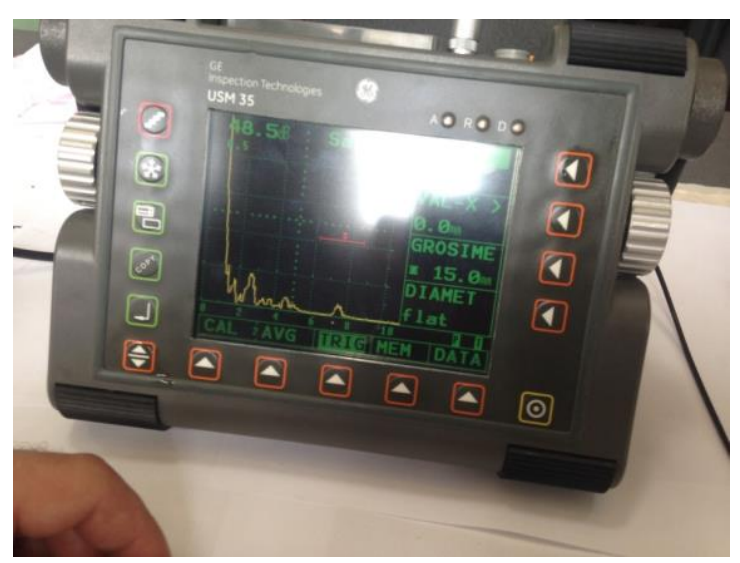

Fig. 8. Krautkramer USM-35 device

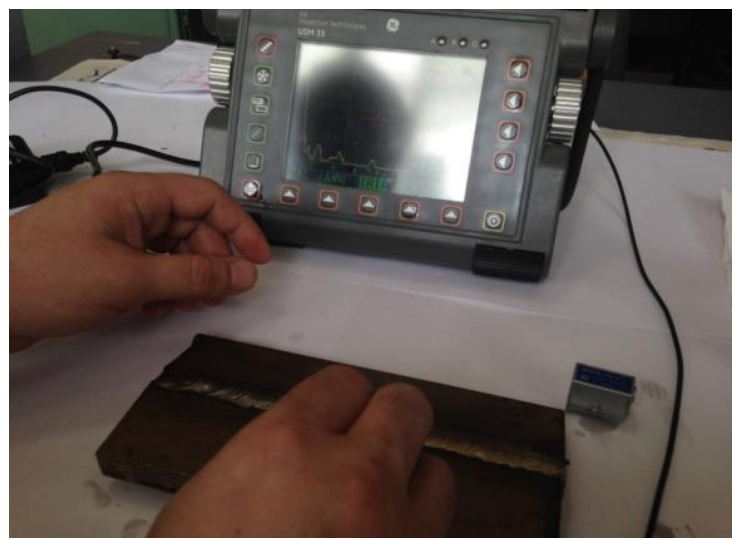

Fig. 9. Ultrasound examination

\section{Conclusions}

The following conclusions have been drawn from the experiments conducted:

- In the case of the Visual Testing and the Penetrant Testing, surface imperfections could be highlighted, as well as the ones in the immediate vicinity of the surface that communicates with the outside surface. Both methods were easy to apply and provided conclusive results.

- In the case of the Magnetic Testing, the results obtained were inconclusive. An impediment can be the low magnetic permeability of stainless steels.

The result obtained by Ultrasound Testing of the welded samples was inconclusive, obtaining only the identification of some big imperfections in the case of sample 2. Ultrasonic Testing of stainless steels is difficult due to the grain size of those steels.

\section{References}

[1]. Paul Kah, Belinga Mvola, Jukka Martikainen, Raimo Suoranta, Real Time Non-Destructive Testing Methods of Welding, Advanced Materials Research, vol. 933, p. 109-116, 2014. 


\section{THE ANNALS OF “DUNAREA DE JOS” UNIVERSITY OF GALATI \\ FASCICLE IX. METALLURGY AND MATERIALS SCIENCE \\ No. 4 - 2018, ISSN 2668-4748; e-ISSN 2668-4756 \\ Article DOI: https://doi.org/10.35219/mms.2018.4.07}

[2]. Bisgrove P., Hayward P., Hirasawa H., Holstein R., Khan A. A., Ooka N., Thiam Siong S., Yzelman W., Guidebook for the Fabrication of Non-Destructive Testing (NDT) Test Specimens, International Atomic Energy Agency (IAEA), Vienna, 2001.

[3]. Oral Büyüköztürk, Mehmet Ali Taşdemir, Nondestructive Testing of Materials and Structures, Springer Science \& Business Media, 2012.

[4]. Jing W., Min-Xu L., Lei Z., Wei C., Ningxu L., Li-Hua H. Effect of welding process on the microstructure and properties of dissimilar weld joints between low alloy steel and duplex stainless steel, vol. 19, no. 6, p. 518-524, 2012
[5]. Mvola B., Kah P., Martikainen J., Dissimilar ferrous metal welding using advanced gas metal arc welding processes, Rev. Adv. Mater. Sci., 38, p. 125-137, 2014.

[6]. ***, EN ISO 5817 - Arc-welded joints in steels - Guidance on quality levels for imperfections. Welding - Fusion welded joints in steel, nickel, titanium and their alloys (beam welding excluded) Quality levels for imperfections.

[7]. ***, EN ISO 6520-1 - Welding and allied processes Classification of geometric imperfections in metallic materials Part 1: Fusion welding. 